\title{
The Social Ecology of Adolescents' Cancer Experience: A Narrative Review and Future Directions
}

\author{
Vanessa Juth ${ }^{1}[$
}

Received: 17 December 2015/Accepted: 30 January 2016/Published online: 17 February 2016

(C) Springer International Publishing 2016

\begin{abstract}
Smaller improvements in survival rates among adolescent patients with cancer relative to their pediatric and older adult counterparts are indicative of a need for greater research pertaining to their unique illness experience. Most recent studies focus on and implicate adolescent patients' distinct cancer biology and unmet needs for specialized treatment as likely explanations, but adolescent patients differ in other ways as well, namely in their intraand interpersonal contexts, or social ecology. Providing better treatment for adolescent cancer patients requires a better understanding of how their social ecology influences and is influenced by their illness. This narrative review provides evidence to support the need for adolescentspecific research focused on the interaction between adolescent patients' cancer experience, their developmental life stage, and the primary relationships within their family unit and healthcare settings. A brief overview of the relevance of each social ecological context is provided, and important considerations for future research efforts and interventions are presented. Conclusions encourage researchers to include adolescent cancer patients' social ecology in their investigations and clinical trials so as to offer this patient cohort the best care possible and eliminate their lag in survival rates.
\end{abstract}

Keywords Adolescents - Cancer - Social ecology · Development · Caregivers · Families · Healthcare

Vanessa Juth

vjuth@hs.uci.edu

1 Program in Nursing Science, Berk Hall, University of California Irvine, Irvine, CA 92697, USA

\section{Introduction}

An estimated nine million people in the United States have endured cancer treatment and its associated physical and psychosocial (i.e., psychological, interpersonal, emotional) consequences since 1971 (Centers for Disease Control and Prevention CDC 2009; Earle and Neville 2004). In the past two decades, prevalence rates for young people diagnosed with all types of cancer have increased substantially (11.4-15.2 cases/100,000; American Cancer Society 2012). Every year, over 70,000 adolescents and young adults between 15 and 39 years of age will be diagnosed with cancer. These numbers are likely to increase in the coming decade as the demographic landscape of the U.S. continually changes to include more diverse ethnic populations who have higher rates of certain types of cancer (American Cancer Society 2012).

Although national cancer survival rates are good ( $\sim 80 \%$ ), adolescent cancer patients of all ethnic backgrounds have not experienced the same increase in survival rates nor quality of life as pediatric and adult patients (e.g., Thomas et al. 2006). From 1973 to 2001, the survival improvement in adolescents is half of what has been observed in children or adult patients (Ries et al. 2007). In fact, cancer is still the leading cause of nonaccidental death among adolescents in the U.S. (Ries et al. 2007). In part, this is because research efforts for adolescent cancer patients have not kept pace with those of other cancer patient cohorts. According to the latest Evidence-based Practice Center reports (U.S. Department of Health and Human Services 2006), the adolescent cancer population has been understudied, which has precluded adolescent patients from receiving "age-appropriate" cancer care (Bleyer et al. 2006). Additionally, a number of reviews agree on a host of other causes that have stymied progress in this population (Bleyer 
2002; Thomas et al. 2006; Zebrack et al. 2010), including that: their cancer biology and tolerance of chemotherapy may differ from pediatric and adult patients, they have a lower adherence to medication and required lifestyle regimens, screening for cancers is more difficult in this age range and detection of the cancer often occurs at a later stage, they may develop unique types of cancer that are not seen in child or adult patients, they are less likely to be referred to a comprehensive multidisciplinary cancer treatment center, and they are treated in pediatric or adult cancer centers that are not specialized for adolescents. Thus, adolescent patients seem to fall into a gap between pediatric and adult oncology services that have limited evidence-based guidelines and standards of care to provide for their unique needs (Zebrack et al. 2010).

This narrative review addresses the understudied developmental and interpersonal aspects of adolescents' cancer experience. Social ecological theory was used to identify the central intra- and inter-personal contexts, and features thereof, that shape adolescents' cancer experience. The literature pertaining to each context was then explored using medical and psychological search engines. The primary aim of this review is to guide future research in further developing the field of adolescent cancer research so as to ultimately help provide the best care and treatment possible for this patient cohort.

\section{The Social Ecology of Adolescent Cancer}

A cancer diagnosis weaves more than a physical illness into the lives of adolescent patients. Disease-related physical complications, frequent medical appointments to monitor treatment outcomes, painful procedures, and numerous medications with uncomfortable or embarrassing side effects become a constant in patients' day-to-day lives. Young patients often feel fatigued and lack the energy to engage in typical activities with their peers. Additionally, serious lifestyle changes, including dietary restrictions, need to be integrated into daily routines. Social activities and interpersonal relationships may also change as friends and family members come to terms with the illness themselves and become uncomfortable talking about it. Fortunately, intermittent positive events, such as a successful procedure, newfound friendships at a treatment clinic, the identification of an effective medication, or encouraging test results also occur. These events reinstate hope about recovery and eventually obtaining a clean bill of health. The continuous fluctuation of unpredictable negative and positive events becomes the focus of adolescents' lives. As such, their cancer experience is defined by their psychological health as well as their social well-being, rather than by their disease alone.
Adolescent patients do not experience cancer in a vacuum; they may be influenced by multiple layers of contextual circumstances-their social ecology. Figure 1 depicts a conceptual model of the social ecological contexts (layers) that shape adolescent patients' cancer experience. The first layer consists of the developmental life stage (intrapersonal context), including biological, psychological, cognitive, emotional and social developmental process unique to adolescents. The second layer is the family unit (primary interpersonal context), in particular, relationships with primary caregivers who provide patients with typical care offered to adolescents (e.g., help with homework, financial support) as well as illness-specific care (e.g., transportation to and from medical visits, treatment decisions, medication adherence, emotional support). The third layer is the healthcare setting (secondary interpersonal context) in which the illness is treated, which includes relationships and interactions with healthcare providers, especially the primary treating oncologist.

Each of these contexts may provide opportunities to intervene and improve adolescent patients' cancer experience. In order for this to occur, a better understanding of these contexts is needed. Plausible ways in which these three contexts influence adolescent patients and how they may be addressed in future research are considered in turn.

\section{Intrapersonal Contexts}

\section{Developmental Life Stage}

A crucial component for adolescent patients' cancer experience that sets them apart from the more commonly studied child or older adult cohorts is their developmental life stage (Ganz 2006). In addition to illness-related

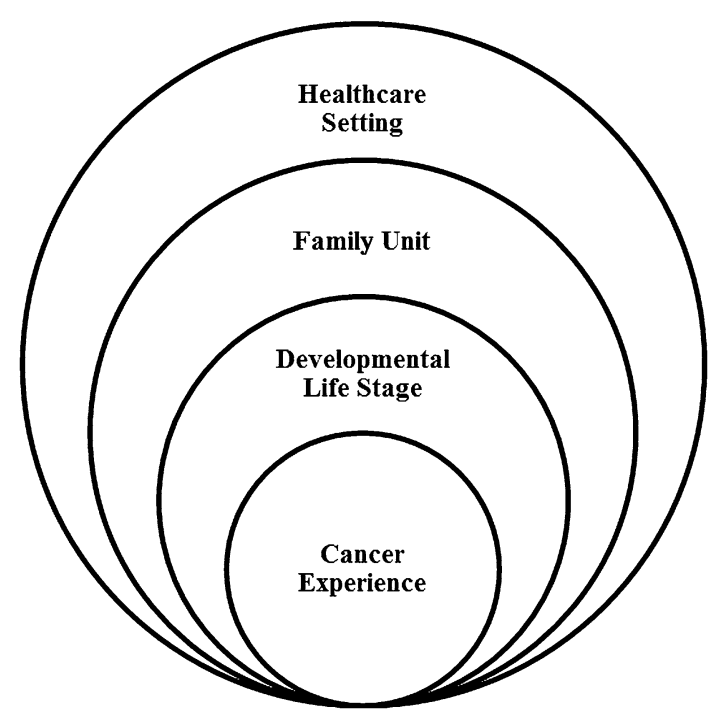

Fig. 1 The social ecology of adolesents' cancer experience 
stressors typically experienced by cancer patients (e.g., frequent medical visits, fatigue, painful procedures), adolescents face the challenge of rapid social, biological, and cognitive changes (Hewitt et al. 2006). In recent years, the previously held linear conceptualization of development has been replaced by a new paradigm that posits that these different transitions of maturation often occur simultaneously (Gorter et al. 2011). This suggests that adolescent patients may be confronted with several different life transitions at any given time, including puberty, identity formation, establishing independence and autonomy from their parents, academic achievements, body image concerns, exploring romantic and sexual relationships, and navigating interpersonal relationships in general (Fritz and McQuaid 2000; Hewitt et al. 2006; Steinberg and Morris 2000)

Presumably, encountering a chronic illness in the context of these transitions can quickly shift an already demanding developmental period into an exceptionally difficult one. Yet, the ways in which developmental aspects of the adolescent patients' lives impact and/or are impacted by their illness is not well-understood. Most of the current discussion of the interactive effects of development and disease is found in reviews or commentaries that rely on speculative theories that lack supportive evidence. The empirical evidence that does exist is based on highly diverse patient populations, the findings of which do not necessarily translate to adolescents with cancer (e.g., adolescents with cancer encounter different illness-related demands and challenges than adolescents with diabetes), or is too sparse to be conclusive on most topics (e.g., adolescent patients engage in riskier behavior than healthy adolescents; Miauton et al. 2003; Suris and Parera 2005). It may be the case that cancer and certain developmental changes have a synergistic effect on adolescent patients' cancer experience, but this has not been adequately assessed.

In order to better understand what factors contribute to the adolescent cancer experience, a higher quantity of studies and designs with a more nuanced approach of examining individual and combinations of developmental features is required. For instance, large-scale epidemiological studies should recruit patients from a wide age range to investigate the linear versus concomitant occurrence of developmental changes. This type of design has the potential to uncover a cumulative risk effect in which more concurrent developmental changes are associated with higher illness-related problems. If linear developmental changes are predominant instead, these changes' differential impacts on adolescent patients' cancer experiences and health can be compared. This could then be used to identify "high impact" developmental changes that are linked with negative biological and psychosocial experiences (e.g., poor recovery, interpersonal conflict). In this way, adolescent cancer patients who are at risk for maladaptive outcomes and poor health trajectories could be identified based on the number or type of developmental changes they are going through and subsequently provided with appropriate social or therapeutic services.

\section{Interpersonal Contexts}

Research on patients with chronic illness demonstrates that they do not go through their illness in isolation. Among individuals with a variety of chronic diseases (e.g., cancer, diabetes, coronary heart disease), social relationships, interpersonal interactions, and social support have been identified as some of the most important predictors of patients' health behaviors (Schiøtz et al. 2012), mental health (Mehnert et al. 2010), quality of life (Kim et al. 2012), disease progression (Barth et al. 2010), and survival time (Lutgendorf et al. 2012). These findings suggest that interpersonal relationships can influence health outcomes by mitigating or exacerbating the negative effects of stress. This is important because different relationships across a number of social contexts can have this impact throughout the course of the illness. To better understand adolescent cancer patients' illness experience, it is essential to consider the two most prominent interpersonal contexts with which they frequently interact: the family unit and the healthcare setting (McCubbin et al. 2002).

\section{The Family Unit}

Among the various social contexts surrounding adolescent cancer patients, the family unit is likely to be the most prominent (Wollenhaupt et al. 2012; World Health Organization 1991). Life changes experienced in adolescence are guided, in part, by the closeness or conflict between adolescents and family members (Sallinen et al. 2007), including their siblings, parents, and sometimes extended family members. However, the relationship with their parental caregiver is thought to be the most influential for adolescents. Although adolescents seek more support from peers and romantic partners as they get older, help-seeking from caregivers and older adults remains stable and relatively high (Laursen and Collins 2009; Markiewicz et al. 2006). Caregivers of cancer patients are estimated to spend up to $40 \mathrm{~h}$ or more per week providing care (National Alliance for Caregiving 2009); this estimate may be even higher for caregivers of adolescent patients since these patients may be limited in their self-sufficiency (e.g., being able to drive to routine appointments, discussing treatment options with healthcare providers), legal authority (e.g., procedural decision-making), and responsibility (e.g., medication adherence, avoiding risky health behaviors). It 
is not surprising, then, that the adolescent-caregiver relationship has such a profound impact on adolescents' psychological well-being, self-esteem, behavior, and selfregulation (Berzonsky et al. 2007; Hair et al. 2008; Heiman et al. 2008; Marin et al. 2008).

Although adolescence marks a time when caregiver guidance may be most useful, adolescents typically report that caregiver relationship quality decreases significantly between the ages of 11 and 14 (McGue et al. 2005). For chronically ill adolescents, the added stress of an unremitting illness may exacerbate tension and conflict with their caregivers as they try to find a balance between obtaining and relinquishing control (Butner et al. 2009). That is not to say that coping with an illness together cannot foster cohesion (Lavee and Mei-Dan 2003), but adapting the adolescent-caregiver relationship to the illness may take time. This is important as both supportive and conflictual interactions with their caregivers have implications for adolescent patients' illness-related psychological adjustment, pain severity, functional disability, and disease management and outcomes (Berg et al. 2008; Logan et al. 2006; Williams et al. 2002).

Patients' illness also have a large impact on caregivers' lives, meaning that caregivers acquire their own "cancer experience", albeit from a different perspective. Providing care to a patient can increase caregivers' vulnerability to psychological and physical dysfunction (Fotiadou et al. 2007; Klassen et al. 2009). In many cases, caregivers' psychological distress was found to be comparable to and even surpass that of patients' (e.g., Hodges et al. 2005; Juth et al. 2015). This is problematic because, in addition to affecting caregivers' well-being, it can also affect patients' cancer experience. For instance, caregivers' psychological distress can directly affect patients by exposing them to caregivers' symptoms or indirectly affect patients by reducing caregivers' ability to provide adequate care. Therefore, future research should make greater efforts to consider caregivers' perspectives and health, and incorporate them into investigations of adolescent patients.

There are three primary limitations characteristic of the literature on cancer patient-caregiver relationships. First, most studies are conducted on adult patients and spousal caregivers (Badr et al. 2010; Ben-Zur 2001; Carmack Taylor et al. 2008; Kim et al. 2007), which may not translate to younger patients and their parental caregivers. For instance, in the case of adolescent patients, caregivers have a clear advantage in the form of authority and power within the relationship; this is unlikely to be the case in spousal or adult relationships.

Second, in the limited research that does examine adolescent cancer patient-caregiver relationships, patients and caregivers are often studied separately. Because adolescent patients and their caregivers go through the cancer experience together, they should be examined as a dyad, or a single social unit comprised of two interdependent individuals (as opposed to two independent individuals; Kenny et al. 2006). In order to elucidate the interpersonal complexities within these dyads, studies should recruit both adolescent patients and their caregivers as this allows for independent self-reports to be collected from each person, which are preferential to proxy reports; such efforts will advance the extant literature in its interpretability and generalizability regarding adolescent patient-caregiver dyads.

Third, if dyadic data do exist, they are often analyzed with statistical techniques that do not adequately account for the intertwined patient-caregiver relationship. Instead, researchers are encouraged to use the Actor-Partner Interdependence Model (APIM; Kenny et al. 2006). The APIM is an advanced statistical approach ideal for examining individuals, such as patients and caregivers, whose experiences are unique yet interrelated. For example, the APIM can help identify contributing sources of psychological adjustment within a patient-caregiver dyad (i.e., who is contributing to whose adjustment) and allows for a comparison of these sources (i.e., who is contributing the most to their own or the other person's adjustment). To date, only one study by Juth et al. (2015) has utilized the APIM in adolescent cancer patients and their caregivers, but an increasing number of studies have recently applied this approach to examine interpersonal phenomena in adult cancer and other chronic diseases (Burkert et al. 2012; Dorros et al. 2010; Manne et al. 2012; Whisman and Uebelacker 2012). This body of evidence demonstrates that assessing either member of the patient-caregiver dyad without the other provides an incomplete understanding of what each person is going through and an inaccurate interpretation of what contributes to their cancer experience. It also suggests that other family members, such as adolescent patients' siblings and caregivers' spouses, should be incorporated into research studies; the illness may have an impact on their relationship with the patient, as well as on their own and the patient's cancer experience.

\section{The Healthcare Setting}

Beyond the family unit, the healthcare setting is reported as the second most influential interpersonal context for patients' cancer experience (McCubbin et al. 2002; Spencer et al. 1998). For adolescent patients specifically, active treatment can include multiple visits per week to outpatient clinics, repeated tests, and exhausting procedures that are highly stressful (Ben-Zur 2001). Because adolescent patients rely heavily on their caregivers during active treatment (e.g., transportation to the hospital, emotional support, managing symptoms), caregivers often attend 
appointments and procedures. In this sense, the patient's healthcare providers treat the patient and the caregiver. Therefore, within the healthcare setting, the illness and its associated issues (treatment decisions, review of test results) are treated within a social system consisting of the adolescent patient, the caregiver, and the healthcare providers (physicians, nurses, medical staff), all of whom influence one another.

Adolescent patients, caregivers, and healthcare providers may influence each other in three specific ways. First, the family (i.e., patient and caregiver) is reliant on healthcare providers for medical services as well as informational and emotional support. The quality of these provisions can render the healthcare setting either a comforting or distressing environment and may influence the family's resilience and psychological, emotional, and physical well-being (McCubbin et al. 2002). Second, the family's cohesion and demeanor is likely to influence the quality of care they receive. Highly distressed or disagreeable families may evoke negative feelings or distress in the healthcare providers, decreasing the effectiveness and quality of their services. Third, healthcare providers themselves acquire their own "cancer experience" in response to the care they provide for each family (Roberts 2010). For example, illness-related stressors (e.g., giving bad news) and/or uncontrollable factors associated with providing healthcare services (e.g., insurance coverage) may result in psychological and emotional distress among healthcare providers (Schwenk et al. 2010). In turn, healthcare providers' well-being may influence the families they treat.

To date, knowledge is limited about how and to what extent healthcare providers and families influence each other in these ways. According to the CDC, there is insufficient evidence about the provisions of healthcare services for young patients and their families to make confident reforms in clinical practice or policy (CDC 2009). One way in which research can assess how families and healthcare providers cope with the illness is with concordance rates between the individual persons (Vance et al. 2001). For example, to ensure patient satisfaction, the care that healthcare providers think they are providing needs to be the same as the care that patients perceive to be receiving. Likewise, healthcare providers' views of the illness need to be similar to patients' and caregivers' views. A lack of concordance between them may affect the quality of care and create tension between them.

Another way to explore these issues is to use specialized statistical approaches that examine dynamic feedback processes. The Social Relations Model is ideal for analyses where multiple units of analysis (e.g., adolescents, caregivers, and healthcare providers) influence and are influenced by each other (Kenny et al. 2006). For instance, the model can examine the associations between a physician's self-reported care provided to the family and how well the patient and caregiver feel cared for. This type of fine-tuned approach can shed light on the dynamics that occur within treatment rooms where important discussions about the patient's well-being take place and critical treatment decisions are made.

Once the interpersonal dynamics within the healthcare setting are better understood they can be used to develop interventions. For instance, communication between healthcare providers and families is a critical component of medical care. Open communication about the disease status and its treatment plan could help minimize distress and ensure a common understanding among families and healthcare providers. Research shows that patients feel more understood and supported when others have empathic accuracy, or share a similar understanding of their illness (Patterson and Garwick 1998). Empathic accuracy within the healthcare setting can help facilitate a unified and cooperative approach among patients, caregivers, and healthcare providers to optimize treatment outcomes (Norfolk et al. 2007; Sultan et al. 2011). Families, especially adolescents' caregivers, can be guided on how to best talk to their healthcare providers so as to optimize the patient's treatment. Likewise, healthcare providers can be better informed about how to communicate with the families they treat. Notably, diverse patient groups (e.g., age, gender) and families (e.g., ethnicity, socioeconomic status) may require distinct approaches for discussing certain medical circumstances (e.g., poor prognosis) (Clarke et al. 2005; Gray et al. 2014; Yin and Twinn 2004). Therefore, future research should take care to examine the specific conditions under which open communication should be encouraged and the ways in which it should be facilitated by healthcare providers and/or clinical therapists.

\section{Additional Influences on Adolescent Patients' Cancer Experience}

Preliminary studies suggest that a number of personal and illness-specific characteristics interact with adolescent patients' intra- and interpersonal contexts. These characteristics may serve as potential determinants of patients' cancer experience, but findings as to which ones are protective or harmful are largely inconsistent (Upton et al. 2008).

\section{Gender Differences}

Gender-specific issues should be taken into account when assessing adolescent patients' developmental and interpersonal contexts as male adolescents typically follow a 
different developmental trajectory than female adolescents. For instance, male adolescent patients may have different concerns (e.g., sexual issues) as compared to female adolescent patients (e.g., body image issues) (Bolte and Zebrack 2008), which may create a different developmental context for each of them. Also, male adolescent cancer patients may be more conflictual or emotionally-distant than female adolescent cancer patients (Seiffge-Krenke 1999), which may impact their relationships with their caregiver and healthcare providers. Moreover, the gender match or mismatch of adolescents and their caregivers has been shown to be important for their relationship (e.g., Hughes and Gullone 2010; Roddenberry and Renk 2008). For instance, male adolescent patients may have more conflict with maternal caregivers than paternal caregivers and therefore may be less resistant to reminders about illness management (e.g., medication adherence) from fathers. Alternatively, female adolescent patients may be closer to maternal caregivers than paternal caregivers and therefore more influenced by their mothers than fathers. Preliminary study results suggest that male and female adolescents with cancer have unique relationships and a different sense of "closeness" with their parents (Carlston and Ogles 2008; Hill et al. 2003), although the findings are mixed as to what type of gender match/mismatch is associated with better or worse outcomes for the patient (Eiser and Morse 2001). It may also be the case that the nature of the relationship (e.g., supportive versus conflictual) matters more than the gender (mis)match, but further evidence is needed to support this.

\section{Family Ethnicity/Race}

The literature suggests that there are ethnic differences in how families define and manage young patients' cancer (Thibodeaux and Deatrick 2007). Ethnic backgrounds and cultural identities are linked with disparate health beliefs (e.g., causes attributed to the illness; Munet-Vilaró 2004), coping strategies (Culver et al. 2002), levels of paternal involvement (Martinson et al. 1999), and treatment needs (Im et al. 2008). These differences may influence adolescent patients' cancer experience, familial interactions, and healthcare treatment. For instance, a family's beliefs about the cause of the illness may influence their willingness to seek medical attention. Moreover, some evidence suggests that ethnic minorities face more barriers to receiving adequate care (Brodie et al. 2002). For example, the need to include translators when making treatment decisions or addressing cultural differences in treatment preferences is often neglected in order to save time (Kelley et al. 2010). This can have implications for adherence to medication regimens or lifestyle changes required for patients' recovery. Unfortunately, research on minority groups in the healthcare system is still in its infancy (USDHHS 2006). Examining the role of ethnicity in adolescent cancer patients is an important avenue for future research as minorities are largely underrepresented in this area (Schwartz et al. 2009) and make up a large part of the patient population (USDHHS 2006).

\section{Caregiver Relationship}

Research has tried to disentangle the experiences of caregivers with different relationships to the patient (e.g., parent, spouse, offspring), but concrete findings have not been replicated. Most studies on caregivers of chronically ill adolescents focus on mothers (Field and Duchoslav 2009) and findings demonstrate that better maternal functioning is associated with better adjustment, functioning, and treatment outcomes in the adolescent patients (Drotar 1997; Kazak et al. 2003). However, fathers also influence their children's well-being (Weitzman et al. 2011) and play a part in adolescent cancer patients' adjustment (Field and Duchoslav 2009). Some evidence suggests that children with chronic conditions have more in common with their mothers than their fathers regarding how (severely) they perceive their illness (e.g., Morrow et al. 2011), but there is little research specifically designed to test this. An important next step in research on adolescent cancer is to increase recruitment of paternal (and other types of) caregivers in studies to gain further understanding of their relationship with the patient and their impact on patients' illness experience.

\section{Clinical Diagnostic Characteristics}

Patients' health as well as their intra- and interpersonal contexts may vary according to the clinical diagnostic characteristics of their illness. For instance, dyadic interactions in the patient-caregiver relationship may be very supportive at the time of diagnosis as both individuals are suddenly faced with a crisis, but may diminish or be replaced with conflict as the illness takes its course and the dyad faces more and repeated obstacles. Most commonly, type of cancer, stage of cancer, and/or time since diagnosis are examined in relation to patients' health, psychological adjustment, and personal relationships, but the findings are largely inconsistent (Bennett et al. 2012; Goldbeck 2011; Sloper 2000). For example, some evidence suggests that patients' impairment is associated with more caregiver distress (Canning et al. 1996), whereas other research finds no change in caregiver strain during different stages of the illness nor over time (Freeman et al. 2004; Hutchinson et al. 2009). Studies should examine patients and their families starting at diagnosis and follow them over the course of their illnesses to determine whether important 
Table 1 Key points for future research

Examine how developmental changes affect adolescent cancer patients' illness experience

Examine the nature of the relationship between adolescent cancer patients and their caregivers, as well as how they influence each other's illness-related adjustment and coping processes

Examine the interpersonal dynamics and concordance between adolescent cancer patients, caregivers, and healthcare providers

Utilize appropriate statistical techniques to examine interactional social phenomena within adolescent cancer patients' interpersonal contexts

Develop and assess interventions for adolescent cancer patients and their families within and outside of the healthcare setting

Consider how personal characteristics (e.g., age, gender, ethnicity/culture) and clinical diagnostic factors are associated with adolescent cancer patients' illness experience and social ecological contexts

illness duration milestones are identifiable. Comparing interpersonal contexts of patients with different types of cancer and risk prognoses in various disease stages would also be fruitful for understanding the bidirectional effects between adolescent patients' cancer experiences and pathophysiology.

\section{Implications for Interventions}

A critical aspect of providing successful interventions that can improve adolescent patients' cancer experience is recognizing that they exist in a complex, interactive system with multiple contributing contexts. A better understanding of how adolescent cancer patients' developmental life stage shape their illness experience can help us design more effective clinical treatments for their unique needs. Likewise, learning more about the important relationships on which adolescent patients rely for support and care within both their family and their healthcare setting can elucidate high-leverage targets for interventions; interpreting psychological outcomes without considering the influence of social ecological contexts could lead to false conclusions about patients' mental and physical health and about the therapeutic and clinical treatments they require. In short, greater efforts to study adolescent cancer patients in light of their social ecological contexts may provide critical insights for developing highly effective interventions.

Furthermore, adolescents' social ecological contexts, particularly the family unit, are also important in terms of preventative cancer interventions. A large literature emphasizes parents as having an integral role in adolescents' health behaviors linked to cancer (e.g., smoking cigarettes, Mays et al. 2014; drinking alcohol, Mares et al. 2012; tanning bed use, Holman and Watson 2013; human papillomavirus vaccination, Holman et al. 2014; nutrition, Larsona et al. 2013; exercise, Sukys et al. 2014). Although this topic extends beyond the scope of the present review, cancer researchers may turn to that literature to gain additional ideas for implementing interventions directed at social ecological contexts of adolescent cancer patients.

\section{Conclusions}

Adolescent cancer remains a specialized field of medicine and health psychology. The cancer experience for these young patients is marked by continuous waves of uncertainty and frequent stressors that are undoubtedly influenced by their developmental life stage and the relationships within their family unit and healthcare setting. The current understanding of how these intra- and interpersonal contexts contribute to and are influenced by adolescent patients' cancer experience is largely based on evidence from other literatures and from preliminary studies of this specific patient population. This review focused on key points for future directions in adolescent cancer research, highlighted in Table 1 , so that the field may: (1) better understand and improve the lives and experiences of adolescent cancer patients, and (2) enhance the likelihood that their caregivers and healthcare providers will make positive contributions to their psychological, emotional and physical health outcomes. More broadly, addressing the knowledge gaps outlined in this review will further inform therapeutic and medical professionals' understanding of how patients and families cope with cancer within and outside healthcare settings. Increasing efforts to conduct social ecological research on adolescents with cancer will help ensure that they receive optimal psychosocial and medical care.

Acknowledgments The contributions of Drs. Leonard Sender, MD, and Roxane Cohen Silver, PhD, are gratefully acknowledged.

\section{Compliance with Ethical Standards}

Conflict of interest The author indicates no potential conflicts of interest. The manuscript represents valid work and neither this manuscript-nor one with similar content-has been published elsewhere. 
Ethical Approval This article does not contain any studies with human participants or animals performed by the author.

\section{References}

American Cancer Society. (2012). Cancer facts \& figures 2012. Atlanta, GA: American Cancer Society.

Badr, H., Camarck, C. L., Kashy, D. A., Cristofanilli, M., \& Revenson, T. A. (2010). Dyadic coping in metastatic breast cancer. Health Psychology, 29, 169-180.

Barth, J., Schneider, S., \& von Känel, R. (2010). Lack of social support in the etiology and the prognosis of coronary heart disease: A systematic review and meta-analysis. Psychosomatic Medicine, 72, 229-238.

Bennett, E., English, M., \& Rennoldson, M. (2012). Predicting parenting stress in caregivers of children with brain tumours. Psycho-Oncology, 22, 629-636.

Ben-Zur, H. (2001). Your coping strategy and my distress: Interspouse perceptions of coping and adjustment among breast cancer patients and their spouses. Families, Systems and Health, 19, 83-94.

Berg, C. A., Schindler, I., \& Maharajh, S. (2008). Adolescents' and mothers' perceptions of the cognitive and relational functions of collaboration and adjustment in dealing with Type 1 Diabetes. Journal of Family Psychology, 22, 865-874.

Berzonsky, M. D., Branje, S. J. T., \& Meeus, W. (2007). Identityprocessing style, psychosocial resources, and adolescents' perceptions of parent-adolescent relations. The Journal of Early Adolescence, 27, 324-345.

Bleyer, A. (2002). Cancer in older adolescents and young adults: Epidemiology, diagnosis, treatment, survival, and importance of clinical trials. Medical and Pediatric Oncology, 38, 1-10.

Bleyer, A., Budd, T., \& Montello, M. (2006). Adolescents and young adults with cancer: The scope of the problem and criticality of clinical trials. Cancer, 107, 1645-1655.

Bolte, S., \& Zebrack, B. (2008). Sexual issues in special populations: Adolescents and young adults. Seminars in Oncology Nursing, $24,115-119$

Brodie, M., Steffenson, A., Valdez, J., \& Levin, R. (2002). National Survey of Latinos. Menlo Park, California, Washington, DC: Henry J. Kaiser Family Foundation.

Burkert, S., Knoll, N., Luszczynska, A., \& Gralla, O. (2012). The interplay of dyadic and individual planning of pelvic-floor exercise in prostate-cancer patients following radical prostatectomy. Journal of Behavioral Medicine, 35, 305-317.

Butner, J., Berg, C. A., Osborn, P., Butler, J., Godri, C., Fortenberry, K., \& Wiebe, D. (2009). Parent-adolescent discrepancies in adolescents' competence and the balance of adolescent autonomy and adolescent and parent well-being in the context of Type 1 diabetes. Developmental Psychology, 45, 835-849.

Canning, R., Harris, E., \& Kelleher, K. (1996). Factors predicting distress among caregivers to children with chronic medical conditions. Journal of Pediatric Psychology, 21, 735-749.

Carlston, D. L., \& Ogles, B. M. (2008). Age, gender, and ethnicity effects on parent-child discrepancy using identical item measures. Journal of Child and Family Studies, 18, 125-135.

Carmack Taylor, C. L., Badr, H., Lee, L., Pisters, K., Fossella, F., \& Schover, L. (2008). Lung cancer patients and their spouses: Psychological and relationship functioning within 1 month of treatment initiation. Annals of Behavioral Medicine, 36, $129-140$

Centers for Disease Control and Prevention. (2009). Adolescent health. Retrieved from: http://www.cdc.gov/az.
Clarke, S.-A., Davies, H., Jenney, M., Glaser, A., \& Eiser, C. (2005). Parental communication and children's behaviour following diagnosis of childhood leukaemia. Psycho-Oncology, 14, 274-281.

Culver, J. L., Arena, P. L., Antoni, M. H., \& Carver, C. S. (2002). Coping and distress among women under treatment for early stage breast cancer: Comparing African Americans, Hispanics, and non-Hispanic whites. Psycho-Oncology, 11, 495-504.

Dorros, S. M., Card, N. A., Segrin, C., \& Badger, T. A. (2010). Interdependence in women with breast cancer and their partners: An interindividual model of distress. Journal of Consulting and Clinical Psychology, 78, 121-125.

Drotar, D. (1997). Relating parent and family functioning to the psychological adjustment of children with chronic health conditions: What have we learned? What do we need to know? Journal of Pediatric Psychology, 22, 149-165.

Earle, C. C., \& Neville, B. A. (2004). Under use of necessary care among cancer survivors. Cancer, 101, 1712-1719.

Eiser, C., \& Morse, R. (2001). Can parents rate their child's healthrelated quality of life? Results of a systematic review. Quality of Life Research, 10, 347-357.

Field, C., \& Duchoslav, R. (2009). Family influence on adolescent treatment outcomes. In W. O'Donohue \& L. Tolle (Eds.), Behavioral approaches to chronic disease in adolescence: An integrative care approach (pp. 47-54). New York, NY: Springer.

Fotiadou, M., Barlow, J., Powell, L., \& Langton, H. (2007). Optimism and psychological well-being among parents of children with cancer: An exploratory study. Psycho-Oncology, 17, 401-409.

Freeman, K., O'Dell, C., \& Meola, C. (2004). Childhood brain tumours: Parental concerns and stressors by phase of illness. Journal of Pediatric Oncology Nursing, 21, 87-97.

Fritz, G. K., \& McQuaid, E. L. (2000). Chronic medical conditions: Impact on development. In A. J. Sameroff, M. Lewis, \& S. M. Miller (Eds.), Handbook of developmental psychopathology (pp. 277-289). New York, NY: Kluwer.

Ganz, P. A. (2006). Monitoring the physical health of cancer survivors: A survivorship-focused medical history. Journal of Clinical Oncology, 24, 5105-5111.

Goldbeck, L. (2011). Parental coping with the diagnosis of childhood cancer: Gender effects, dissimilarity within couples, and quality of life. Psycho-Oncology, 10, 325-335.

Gorter, J. W., Stewart, D., \& Woodbury-Smith, M. (2011). Youth in transition: Care, health and development. Child Care Health and Development, 37, 757-763.

Gray, W., Szulczewski, L., Regan, S., Williams, J., \& Pai, A. (2014). Cultural influences in pediatric cancer from diagnosis to cure/ end of life. Journal of Pediatric Oncology Nursing, 31, 252-271.

Hair, E. C., Moore, K. A., Garrett, S. B., Ling, T., \& Cleveland, K. (2008). The continued importance of quality parent-adolescent relationships during late adolescence. Journal of Research on Adolescence, 18, 187-200.

Heiman, T., Zinck, L. C., \& Heath, N. L. (2008). Parents and youth with learning disabilities: Perceptions of relationships and communication. Journal of Learning Disabilities, 41, 524-534.

Hewitt, M., Greenfield, S., \& Stovall, E. (2006). From cancer patient to cancer survivor: Lost in transition. Washington DC: National Academies Press.

Hill, J., Kondryn, H., Mackie, E., McNally, R., \& Eden, T. (2003). Adult psychosocial functioning following childhood cancer: The different roles of sons' and daughters' relationships with their fathers and mothers. Journal of Child Psychology and Psychiatry, 44, 752-762.

Hodges, L., Humphries, G. M., \& MacFarlane, G. (2005). A metaanalytic investigation of the relationship between the 
psychological distress of cancer patients and their carers. Social Science and Medicine, 60, 1-12.

Holman, D. M., Benard, V., Roland, K. B., Watson, M., Liddon, N., \& Stokley, S. (2014). Barriers to human papillomavirus vaccination among US adolescents: A systematic review of the literature. JAMA Pediatrics, 168, 76-82.

Holman, D. M., \& Watson, M. (2013). Correlates of intentional tanning among adolescents in the united states: A systematic review of the literature. Journal of Adolescent Health, 52, S52S59.

Hughes, E. K., \& Gullone, E. (2010). Discrepancies between adolescent, mother, and father reports of adolescent internalizing symptom levels and their association with parent symptoms. Journal of Clinical Psychology, 66, 978-995.

Hutchinson, K. C., Willard, V. W., Hardy, K. K., \& Bonner, M. J. (2009). Adjustment of caregivers of pediatric patients with brain tumours: A cross sectional analysis. Psycho-Oncology, 18, 515-523.

Im, E. O., Chee, W., Guevara, E., Lim, H. J., Liu, Y., \& Shin, H. (2008). Gender and ethnic differences in cancer patients' needs for help: An internet survey. International Journal of Nursing Studies, 45, 1192-1204.

Juth, V., Silver, R. C., \& Sender, S. L. (2015). The shared experience of adolescent and young adult cancer patients and their caregivers. Psycho-Oncology, 24, 1746-1753.

Kazak, A. E., Rourke, M. T., \& Crump, T. A. (2003). Families and other systems in pediatric psychology. In M. Roberts (Ed.), Handbook of pediatric psychology (3rd ed., pp. 159-175). New York, NY: Guilford.

Kelley, A. S., Wenger, N. S., \& Sarkisian, C. A. (2010). Opinions: End-of-life care preferences and planning of older Latinos. Journal of American Geriatrics, 58, 1109-1116.

Kenny, D. A., Kashy, D. A., \& Cook, W. L. (2006). Dyadic data analysis. New York, NY: Guilford.

Kim, Y., Carver, C. S., Deci, E. L., \& Kasser, T. (2007). Adult attachment and psychological well-being in cancer caregivers: The mediational role of spouses' motives for caregiving. Health Psychology, 27, 144-154.

Kim, Y., Carver, C. S., Spillers, R. L., Love-Ghaffari, M., \& Kaw, C.K. (2012). Dyadic effects of fear of recurrence on the quality of life of cancer survivors and their caregivers. Quality of Life Research, 21, 517-525.

Klassen, A. F., Dix, D., Cano, S. J., Papsdorf, M., Sung, L., \& Klaassen, R. J. (2009). Evaluating family-centred service in paediatric oncology with the measure of processes of care (MPOC-20). Child Care Health and Development, 35, 16-22.

Larsona, N., Fulkersona, J., Storya, M., \& Neumark-Sztainera, D. (2013). Shared meals among young adults are associated with better diet quality and predicted by family meal patterns during adolescence. Public Health Nutrition, 16, 883-893.

Laursen, B., \& Collins, W. A. (2009). Parent-child relationships during adolescence. In R. M. Lerner \& L. Steinberg (Eds.), Handbook of adolescent psychology: Contextual influences on adolescent development (3rd ed., Vol. 2, pp. 3-42). New York: Wiley.

Lavee, Y., \& Mei-Dan, M. (2003). Patterns of change in marital relationships among parents of children with cancer. Health and Social Work, 28, 255-263.

Logan, D. E., Guite, J. W., Sherry, D. D., \& Rose, J. B. (2006). Adolescent-parent relationships in the context of adolescent chronic pain conditions. Clinical Journal of Pain, 22, 576-583.

Lutgendorf, S. K., De Geest, K., Bender, D., Ahmed, A., Goodheart, M. J., \& Sood, A. K. (2012). Social influences on clinical outcomes of patients with ovarian cancer. Journal of Clinical Oncology, 30, 2885-2890.
Manne, S., Badr, H., \& Kashy, D. A. (2012). A longitudinal analysis of intimacy processes and psychological distress among couples coping with head and neck or lung cancers. Journal of Behavioral Medicine, 35, 334-346.

Mares, S. H. W., Lichtwarck, A., Burk, W. J., van der Vorst, H., \& Engels, R. (2012). Parental alcohol-specific rules and alcohol use from early adolescence to young adulthood. Journal of Child Psychology and Psychiatry, 53, 798-805.

Marin, K. A., Bohanek, J. G., \& Fivush, R. (2008). Positive effects of talking about the negative: Family narratives of negative experiences and preadolescents' perceived competence. Journal of Research on Adolescence, 18, 573-593.

Markiewicz, D., Lawford, H., Doyle, A. B., \& Haggart, N. (2006). Developmental differences in adolescents' and young adults' use of mothers, fathers, best friends, and romantic partners to fulfill attachment needs. Journal of Youth and Adolescence, 35, 121-134.

Martinson, I. M., Leavitt, M., Liu, C., Armstrong, V., Hornberger, L., \& Han, X. (1999). Comparison of Chinese and caucasian families caregiving to children with cancer at home: Part I. Journal of Pediatric Nursing, 14, 99-109.

Mays, D., Gilman, S. E., Rende, R., Luta, G., Tercyak, K. P., \& Niaura, R. S. (2014). Parental smoking exposure and adolescent smoking trajectories. Pediatrics, 133, 983-991.

McCubbin, M., Balling, K., Possin, P., Friedrich, S., \& Bryne, B. (2002). Family resilience in childhood cancer. Family Relations, $51,103-111$.

McGue, M., Elkins, I., Walden, B., \& Iacono, W. G. (2005) Perceptions of the parent-adolescent relationship: A longitudinal investigation. Developmental Psychology, 41, 971-984.

Mehnert, A., Lehmann, C., Graefen, M., Huland, H., \& Koch, U. (2010). Depression, anxiety, post-traumatic stress disorder and health-related quality of life and its association with social support in ambulatory prostate cancer patients. European Journal of Cancer Care, 19, 736-745.

Miauton, L., Narring, F., \& Michaud, P. A. (2003). Chronic illness, lifestyle and emotional health in adolescence: Results of a crosssectional survey on the health of 15-20 year-olds in Switzerland. European Journal of Pediatrics, 162, 682-689.

Morrow, A. M., Hayen, A., Quine, S., Scheinberg, A., \& Craig, J. C. (2011). A comparison of doctor's, parents' and children's reports of health states and health-related quality of life in children with chronic conditions. Child Care Health, and Development, 38, 186-195.

Munet-Vilaró, F. (2004). Delivery of culturally competent care to children with cancer and their families-The Latino experience. Journal of Pediatric Oncology Nursing, 21, 155-159.

National Alliance for Caregiving. (2009). Caregiving in the U.S. 2009. Retrieved online from: http://www.caregiving.org/ research.

Norfolk, T., Birdi, K., \& Walsh, D. (2007). The role of empathy in establishing rapport in the consultation: A new model. Medical Education, 41, 690-697.

Patterson, J. M., \& Garwick, A. W. (1998). Theoretical linkages: Family meanings and sense of coherence. In H. I. McCubbin, E. A. Thompson, A. I. Thompson, \& J. E. Fromer (Eds.), Stress, coping and health in families (pp. 71-89). Thousand Oaks, CA: Sage.

Ries, L.A.G., Melbert, D., Krapcho, M., Mariotto, A., Miller, B.A., \& Edwards, B.K. (Eds.). (2007). SEER Cancer Statistics Review, 1975-2004, National Cancer Institute. Bethesda, MD, http:// seer.cancer.gov/csr/1975_2004/, based on November 2006 SEER data submission, posted to the SEER web site.

Roberts, L. W. (2010). Understanding depression and distress among medical students. Journal of the American Medical Association, 304, 1231-1233. 
Roddenberry, A., \& Renk, K. (2008). Quality of life in pediatric cancer patients: The relationships among parents' characteristics, children's characteristics, and informant concordance. Journal of Child and Family Studies, 17, 402-426.

Sallinen, M., Rönkä, A., Kinnunen, U., \& Kokko, K. (2007). Trajectories of depressive mood in adolescents: Does parental work or parent-adolescent relationship matter? A follow-up study through junior high school in Finland. International Journal of Behavioral Development, 31, 181-190.

Schiøtz, M. L., Bøgelund, M., Almdal, T., Jensen, B. B., \& Willaing, I. (2012). Social support and self-management behaviour among patients with Type 2 diabetes. Diabetic Medicine, 29, 654-661.

Schwartz, L. A., Kazak, A. E., \& Mougianis, I. (2009). Cancer. In W. O'Donohue \& L. W. Tolle (Eds.), Behavioral approaches to chronic disease in adolescence: An integrative care approach (pp. 197-217). New York, NY: Springer.

Schwenk, T. L., Davis, L., \& Wimsatt, L. A. (2010). Depression, stigma and suicidal ideation in medical students. Journal of the American Medical Association, 304, 1181-1190.

Seiffge-Krenke, I. (1999). Families with daughters, families with sons: Different challenges for family relationships and marital satisfaction? Journal of Youth and Adolescence, 28, 325-342.

Sloper, P. (2000). Predictors of distress in parents of children with cancer: A prospective study. Journal of Pediatric Psychology, $25,79-91$.

Spencer, S. M., Carver, C. S., \& Price, A. A. (1998). Psychological and social factors in adaptation. In J. Holland (Ed.), PsychoOncology (pp. 255-284). San Francisco, CA: Jossey-Bass.

Steinberg, L., \& Morris, A. (2000). Adolescent development. Annual Review of Psychology, 52, 83-110.

Sukys, S., Majauskienè, D., Cesnaitiene, V. J., \& Karanauskiene, D. (2014). Do parents' exercise habits predict 13-18 year old adolescents' involvement in sport? Journal of Sports Science and Medicine, 13, 522-528.

Sultan, S., Attali, C., Gilberg, S., Zenasni, F., \& Hartemann, A. (2011). Physicians' understanding of patients' personal representations of their diabetes: Accuracy and association with selfcare. Psychology and Health, 26, 101-117.

Suris, J. C., \& Parera, N. (2005). Sex, drugs and chronic illness: Health behaviors among chronically ill youth. European Journal of Public Health, 15, 484-488.
Thibodeaux, A., \& Deatrick, J. A. (2007). Cultural influence on family management of children with cancer. Journal of Pediatric Oncology Nursing, 24, 227-233.

Thomas, D. M., Seymour, J. F., O'Brien, T., Sawyer, S. M., \& Ashley, D. M. (2006). Adolescent and young adult cancer: A revolution in evolution? Internal Medicine Journal, 36, 302-307.

Upton, P., Lawford, J., \& Eiser, C. (2008). Parent-child agreement across child health-related quality of life instruments: A review of the literature. Quality of Life Research, 17, 895-913.

U.S. Department of Health and Human Services. (2006). Cancer care quality measures: Symptoms and end-of-life care. (Agency for Healthcare Research and Quality Publication No. 06-E001.) Retrieved from: http:// www.ahrq.gov/clinic/epcindex.htm\#hematology.

Vance, Y. H., Morse, R. C., Jenney, M. E., \& Eiser, C. (2001). Issues in measuring quality of life in childhood cancer: Measures, proxies, and parental mental health. Journal of Child Psychology and Psychiatry, 42, 661-667.

Weitzman, M., Rosenthal, D. G., \& Liu, Y.-H. (2011). Paternal depressive symptoms and child behavioral or emotional problems in the United States. Pediatrics, 128, 1-9.

Whisman, M. A., \& Uebelacker, L. A. (2012). A longitudinal investigation of marital adjustment as a risk factor for metabolic syndrome. Health Psychology, 31, 80-86.

Williams, P. G., Holmbeck, G. N., \& Greenley, R. N. (2002). Adolescent health psychology. Journal of Consulting and Clinical Psychology, 70, 828-842.

Wollenhaupt, J., Rodgers, B., \& Sawin, K. J. (2012). Family management of a chronic health condition: Perspectives of adolescents. Journal of Family Nursing, 18, 65-90.

World Health Organization. (1991). Statistical indices of family health: Report of a WHO study group (Technical report series No. 589). Geneva, Switzerland: World Health Organization.

Yin, L. K., \& Twinn, S. (2004). The effect of childhood cancer on Hong Kong Chinese families at different stages of disease. Cancer Nursing, 27, 17-24.

Zebrack, B., Mathews-Bradshaw, B., \& Siegel, S. (2010). Quality cancer care for adolescents and young adults: A position statement. Journal of Clinical Oncology, 28, 4862-4867. 